\title{
A Statistics-Based Study on Wood Presentation of Modern Wood Building Facades
}

\author{
Hongpeng $\mathrm{Xu}^{1,2}$, Jing $\mathrm{Li}^{1,2}$, MengXuan $\mathrm{Li}^{3}$, and Jianmei $\mathrm{Wu}^{1,2, *}$ \\ ${ }^{1}$ School of Architecture, Harbin Institute of Technology, 150001, Harbin, China \\ ${ }^{2}$ Key Laboratory of Cold Region Urban and Rural Human Settlement Environment Science and Technology, Ministry of Industry and \\ Information Technology, 150001, Harbin, China \\ ${ }^{3}$ Beijing planning committee yanqing branch, 102100, Beijing, China
}

\begin{abstract}
Wood presentation of modern wood building facades relating to the expression of the essential characteristics of architecture, utilization efficiency of wood and acceptance of architectural image,etc. However, relevant studies are obviously insufficient. This paper makes a statistical analysis of outstanding wood structure space cases which be selected, tries to reveal the expression rule of major timber application variables of wood coverage, materials collocation, wood form and wood color under the limitation of the main influencing factors of building function, building form and building scale. The purpose of this study is to explore the wood presentation rule of modern wood building Facades under the influence of building factors.
\end{abstract}

\section{Introduction}

Modern wood building as an environmentally friendly green building, has become a key research object of architecture design.But modern wood building in China has only been developing for nearly 30 years.Up to now, the proportion of wood building is less than $1 \%$, therefore, the country has set a goal of increasing the proportion of wood building to $5 \%$ during China's 13 th plan of five-year national development. wood presentation of modern wood building facades is the main way to express the characteristics of wood building and one of the most important aspects in architectural creation. However, facade design of modern wood building exist some serious phenomena such as material accumulation, disorderly design methods, lack of aesthetic feeling etc.

Domestic researches on wood building performance mainly focus on the application mode of wood in architecture and the expression form of components. Among them, the most representative studies are Chenrong's and feng jin's. Chenrong's paper set out to the composition elements of "rods, plain and blocks", briefly introduces the composition methods of different skin interfaces, and lists some typical cases abroad. Fengjin's paper explores the innovative application of wood in architecture from four perspectives of structure, enclosure, epidermis and internal component[1,2]. The existing studies have shown the great value of the excellent cases, but still remain at the level of illustration and elaboration, without quantitative statistical analysis. And there is a lack of quantitative analysis of possible impact on building function, building shape, building scale and exterior epidermal wood performance. Foreign countries have introduced more scientific methods, such as quantitative research, to study the wood performance since the 1980s, but all aimed at interior space. the research on the wood performance of the building skin started in the 21st century[3]. In 2008, J Ken Shuttleworth and Principal Make began to study the skin morphology of high-rise buildings and put forward other wood skin texture forms besides the all-glass skin[4]. In 2012, J Siem compare the differences of timber as building materials in architectural performance through physical modeling and digital modeling[5]. In 2016, Harumi Ikei found that relevant studies were increasing year by year through reviewed 41 papers about wood application performance that published at the world conference on timber construction between 1992 and 2016[6]. And there are nearly 10 papers about wood application performance published on the world conference on timber construction in 2018. Although the content is increasingly, there is also a lack of quantitative studies using case statistics as a method.

This paper is based on excellent case statistics, by combining subjective and objective to explore the characteristics and influence factors of wood presentation on the facade of modern wooden buildings. Aim to summarize the rule of wood presentation on the facade,so that timber resources can be used more rationally and effectively under the influence of specific factors.

\section{Case statistics}

Corresponding author: wimtutu@126.com 
Research based on the statistics of excellent cases explored the wood performance influencing factors of modern wooden buildings facade and the factors influencing the wood presentation, and further explore significant degree of factor influence and characteristics of wood presentation under specified factors.

\subsection{Case selection}

Case selection is the basis and premise of the study. The selection criteria are modern wood buildings with wood on the facade which are characterized by quality, universality, typicality and timeliness, the construction time is between 2012 and 2017. The specific principles and requirements are shown in Table 1.

Table 1. Caseselection principles and requirements.

\begin{tabular}{|c|c|c|}
\hline Principlrs & Requirements & Scource \\
\hline Quality & $\begin{array}{l}\text { 1. Published in } \\
\text { influential } \\
\text { magazines and } \\
\text { websites } \\
\text { 2. Awarded } \\
\text { Architecture }\end{array}$ & \multirow{3}{*}{$\begin{array}{l}\text { Website: } \\
\text { DEZEEN is the most } \\
\text { influential architectural } \\
\text { design blog in the world } \\
\text { Magazine: } \\
\text { Architecture detail: Wood } \\
\text { architecture and wood } \\
\text { structure album } \\
\text { DEZEEN WOODEN } \\
\text { BUILDING ALBUM } \\
\text { AWARDS: } \\
\text { WOOD AWARDS、 } \\
\text { WOOD DESIGN } \\
\text { AWARD、 } \\
\text { AUSTRALIAN TIMBER } \\
\text { DESIGN AWARDS }\end{array}$} \\
\hline Universality & $\begin{array}{l}\text { 1. Universal and } \\
\text { comprehensive cases } \\
\text { 2. No limitations to } \\
\text { the case background }\end{array}$ & \\
\hline Timeliness & $\begin{array}{l}\text { 1. Construction } \\
\text { technology fits the } \\
\text { current environment } \\
\text { 2. Materials fit the } \\
\text { modern technology }\end{array}$ & \\
\hline Total & & 280 \\
\hline
\end{tabular}

\subsection{Determine wood presentation factor and level}

First, identify wood presentation key variables through focus group. According to references, it is appropriate to organize 6-12 people to participate in the discussion. Focus group organized 10 persons (including 1 question-master and 1 recorder) with professional background in architecture and a certain understanding of modern wood building to participate in this discussion, The question-master guided the participants to discuss according to the prepared questions.

The wood presentation factor is the medium in which the wood shows its characteristics in the building, which is the main object of this research, while the level is the vertical division of each medium for more explicit statistical analysis. Discussors considered that the main media for wood characteristics were color, wood shape, texture, luster, material collocation, dosage, application site, technical characteristics, etc. Interactive discussion shows that the wood application site and technical characteristics are mainly obvious in the indoor performance; For wood texture and luster, it is not easy to be captured due to the long distance of outdoor viewing. The results showed that the key wood presentation factors were wood coverage rate, materials matching, wood shape and wood color. Then the level of presentation factors can be determined through cases.

- Wood coverage rate: In this study, the wood coverage rate is defined as the ratio between the wood covered area and the visible solid area of the building (besides the area of doors and windows) in the picture. In order to ensure that there are sufficient number of cases in each level sub-item and the span cannot be too large, the wood coverage rate is divided into 5 levels by $20 \%$.

- Material collocation: white plaster, concrete and stone are commonly selected to be matched with wood in facade of modern wooden buildings, to create a natural, simple and modern visual effect.Shown in figure 1 .

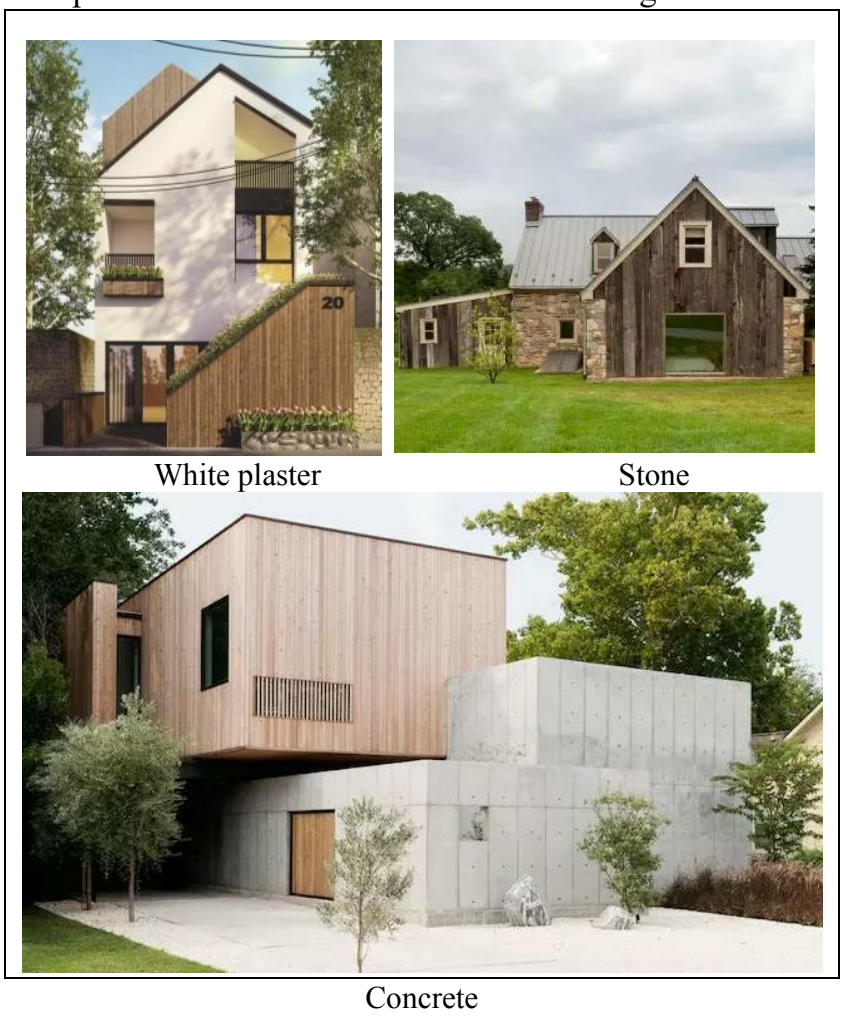

Fig. 1. Matching material level and case indication.

- Wood texture:The wood texture is the basic unit that forms the facade. According to the selected cases, the wood texture can be divided into three forms: surface, line and point.Shown in figure 2.

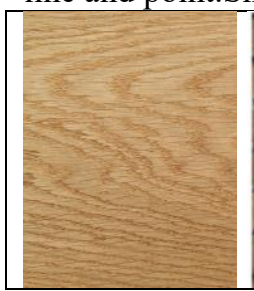

Surface

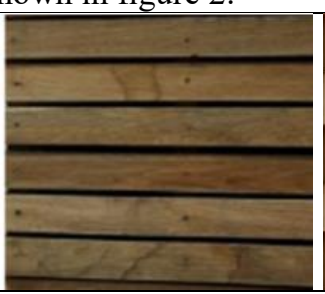

Lin

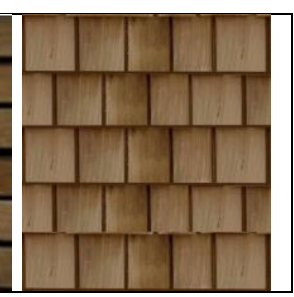

Point
Fig. 2. Wood texture level and case indication.

- Wood color: According to the selected cases, the color of the exterior timber of the building can be divided into natural color, low brightness color and high brightness color. Natural color is mainly yellow or red 
warm color to create a warm feeling. Low brightness color basically is heavy color such as slant black or dullred, in order to build composed, massiness feeling. high brightness color basically is grayish white or other bright color, in order to build lightsome, lively feeling. Shown in figure 3.

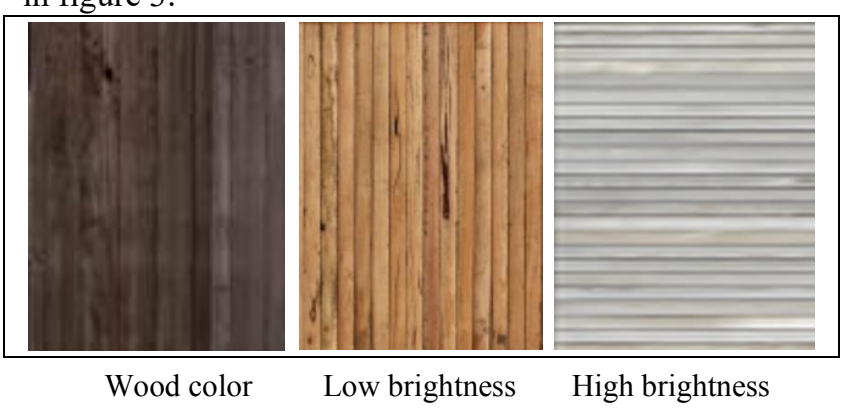

Fig. 3. Wood color level and case indication.

Through the preliminary statistics and comprehensive analysis of the selected case pictures, wood presentation factors was divided horizontally (Table 2 ).

Table 2. Factor level of exterior epidermis of wood structure building.

\begin{tabular}{|c|c|c|c|c|}
\hline \multirow{2}{*}{ Levels } & \multicolumn{4}{|c|}{ Influence factors } \\
\cline { 2 - 5 } & $\begin{array}{c}\text { Amount } \\
\text { of wood } \\
(\%)\end{array}$ & $\begin{array}{c}\text { Material } \\
\text { combinations }\end{array}$ & $\begin{array}{c}\text { Wood } \\
\text { patterns }\end{array}$ & $\begin{array}{c}\text { wood } \\
\text { color }\end{array}$ \\
\hline 1 & $0-20$ & White plaster & Plain & $\begin{array}{c}\text { Low } \\
\text { brightness } \\
\text { color }\end{array}$ \\
\hline 2 & $21-40$ & Concrete & $\begin{array}{c}\text { With } \\
\text { lines }\end{array}$ & $\begin{array}{c}\text { Natural } \\
\text { color }\end{array}$ \\
\hline 3 & $41-60$ & Stone & With & $\begin{array}{c}\text { High } \\
\text { brightness } \\
\text { color }\end{array}$ \\
\hline 4 & $61-80$ & & & \\
\hline 5 & $81-100$ & & & \\
\hline
\end{tabular}

The different presentation of modern wood building facades determines the visual effect conveyed by the buildings and affects the visual quality of urban space, it is also the basic starting point for the audience to perceive the quality of wood building. It is easy for designers to clarify which media can be used to create a good visual effect of wood buildings after defining the variable and level of wood presentation on the facade of wood buildings.

\subsection{Determine influence factor and level}

The presentation rule of wood is affected by many factors, which are more complex. Therefore, it is necessary to extract the key influence factors as the conditions for further study. In this study, focus group was used to determine influence factors.

Discussors think that the factors influencing the presentation of wood building facade may be the building shape, building scale, building function, building Surrounding environment, designer's cognition, etc. Interactive discussion shows that designers' cognitive factors are too subjective to be followed regularly. Through the collected cases, it is found that most of the wood buildings have a good landscape environment, so this influencing factor is not taken into consideration for the time being. Finally, the key factors affecting wood presentation were selected as building shape, building scale and building function.

According to the results of the interactive discussion and the data summary, the key influencing factors divided horizontally:

- Building function: mainly divided into entertainment, office and education.

- Building shape: mainly divided into single shape and pluralistic shape. Single shape means that the building is only a basic geometric form. pluralistic shape refers to a variety composition of shapes that are composed of similar or different shapes as basic units through certain logic and methods.

- Building scale: mainly divided into small, medium and large three types. Small-scale refers to building with the area of under $300 \mathrm{~m}^{2}$, layer number of no more than two layers; Medium-scale refers to building with the area in $300 \sim 1000 \mathrm{~m}^{2}$ within one to three layers; large-scale refers to building with the area more than $1000 \mathrm{~m}^{2}$.

\subsection{Orthogonal experiment design}

Design orthogonal experiment based on the factors identified above. Through orthogonal experiment to explore significant difference and important order of factors that affect wood presentation and determine the optimal level combination. Orthogonal experiment is an effective research method in factor analysis to study multi-factors and multi-levels, It is based on orthogonality to select the representative points from the comprehensive test. Through orthogonal experiment can find better influence condition through few times of experiment.

Table 3. Factors level that affecting wood presentation.

\begin{tabular}{|c|c|c|c|}
\hline \multirow{2}{*}{ Levels } & \multicolumn{3}{|c|}{ Influence factors } \\
\cline { 2 - 4 } & $\begin{array}{c}\text { Building } \\
\text { function }\end{array}$ & Building shape & $\begin{array}{c}\text { Building } \\
\text { scale }\end{array}$ \\
\cline { 2 - 4 } & $\mathrm{A}$ & $\mathrm{B}$ & $\mathrm{C}$ \\
\hline 1 & Office & Single shape & Small-scale \\
\hline 2 & Education & $\begin{array}{c}\text { Pluralistic } \\
\text { shape }\end{array}$ & $\begin{array}{c}\text { Medium- } \\
\text { scale }\end{array}$ \\
\hline 3 & Entertainment & & Large-scale \\
\hline
\end{tabular}

In order to explore the influence of building function, building shape and building scale on the presentation of modern wood building facade, arrange 3 factors muilt level orthogonal experiment, experimental factor's level shown in table 3, experimental index is the number of cases. The factors A and C take 3 levels, factor B take 2 levels,no interaction was observed. The experiment was arranged by the quasi-horizontal method, and the level of factor B was virtualized to make it into 3 levels. L9 $\left(3^{4}\right)$ was selected as the orthogonal table to design the experiment. The test scheme is shown in table 4 . 
Table 4. Test scheme

\begin{tabular}{|c|c|c|c|c|c|c|}
\hline \multirow{3}{*}{ Test number } & \multicolumn{5}{|c|}{ Test factors } & \multirow{3}{*}{$\begin{array}{c}\text { Statistical } \\
\text { result }\end{array}$} \\
\hline & $\mathrm{A}$ & \multicolumn{2}{|r|}{$\mathrm{B}$} & $\mathrm{C}$ & Vacant column & \\
\hline & 1 & 2 & $2^{\prime}$ (Virtual column) & 3 & 4 & \\
\hline 1 & 1 & 1 & 1 & 1 & 1 & 4 \\
\hline 2 & 1 & 2 & 2 & 2 & 2 & 14 \\
\hline 3 & 1 & 3 & 2 & 3 & 3 & 8 \\
\hline 4 & 2 & 1 & 1 & 2 & 3 & 3 \\
\hline 5 & 2 & 2 & 2 & 3 & 1 & 10 \\
\hline 6 & 2 & 3 & 2 & 1 & 2 & 5 \\
\hline 7 & 3 & 1 & 1 & 3 & 2 & 16 \\
\hline 8 & 3 & 2 & 2 & 1 & 3 & 15 \\
\hline 9 & 3 & 3 & 2 & 2 & 1 & 115 \\
\hline
\end{tabular}

\subsection{Ensure statistical method}

This study followed statistical method, the ratio of cases defined by specific conditions of to total cases as the basic description index, According to the factors influencing wood presentation in each case, the corresponding factor level is weighted by 1 , and the number of times each factor level appears in all cases is added up.SPSS statistics software was used to calculate the case ratio, $F$ value and significance of different influencing factors. The larger the ratio, the more cases were defined, and the larger the $\mathrm{F}$ value, the more important the impact of factors, $\mathrm{P}<0.05$ had statistical significance.

\section{Statistical analysis}

\subsection{Significance analysis of influencing factors}

Building form, building function and building scale are the factors that architects need to consider at the beginning of design, so as to define the significant degree of the influence of the factors, so as to clarify the primary and secondary factors in the design of wood construction, so as to clarify the characteristics of wood performance.

Table 5. Orthogonal experiment statistical results

\begin{tabular}{|c|c|c|c|c|c|}
\hline Soruce & $\begin{array}{c}\text { Degree } \\
\text { of } \\
\text { freedom }\end{array}$ & $\mathrm{K}$ & $\begin{array}{c}\text { Standard } \\
\text { deviation }\end{array}$ & $\mathrm{F}$ & $\begin{array}{c}\text { Signif } \\
\text {-icance }\end{array}$ \\
\hline $\mathrm{A}$ & 2 & $\begin{array}{c}\mathrm{K}_{\mathrm{A} 1}=26 \\
\mathrm{~K}_{\mathrm{A} 2}=18 \\
\mathrm{~K}_{\mathrm{A} 3}=146\end{array}$ & 0.65 & 1183.05 & $* *$ \\
\hline $\mathrm{B}$ & 1 & $\begin{array}{c}\mathrm{K}_{\mathrm{B} 1}=23 \\
\mathrm{~K}_{\mathrm{B} 2}=39\end{array}$ & 0.69 & 362.52 & $*$ \\
\hline $\mathrm{C}$ & 2 & $\begin{array}{c}\mathrm{K}_{\mathrm{C} 1}=24 \\
\mathrm{~K}_{\mathrm{C} 2}=132 \\
\mathrm{~K}_{\mathrm{C} 3}=34\end{array}$ & 0.49 & 420.44 & $* *$ \\
\hline
\end{tabular}

The correlation is significant at the level of 0.01 (both tails)

The correlation is significant at the level of 0.05 (both tails)

Table 5 shows the results of the analysis of orthogonal experiment, the result indicate that there is significant variance in factor B and extremely significant variance in factor $\mathrm{A}$ and $\mathrm{C}$. By comparing $\mathrm{F}$ value, it can be determined that the important order of the factors is $\mathrm{A}>\mathrm{C}>\mathrm{B}$; By comparing $\mathrm{K}$ value, it can be determined that the optimal level combination is $\mathrm{A}_{3} \mathrm{~B}_{2} \mathrm{C}_{2}$, that is, the most outstanding wood building with medium scale, pluralistic shape and function of entertainment are the most.

Based on the results of significant analysis, analyzed the presentation characteristics of outstanding wood building facade limited by most influence factor and optimal level combination.

\subsection{Wood presentation research under the factor of building function}

Research shows that under the influence of building function, building form and building scale, building function plays a leading role, so this part analyzes the characteristics of timber performance according to the excellent timber building cases limited by different building functions.

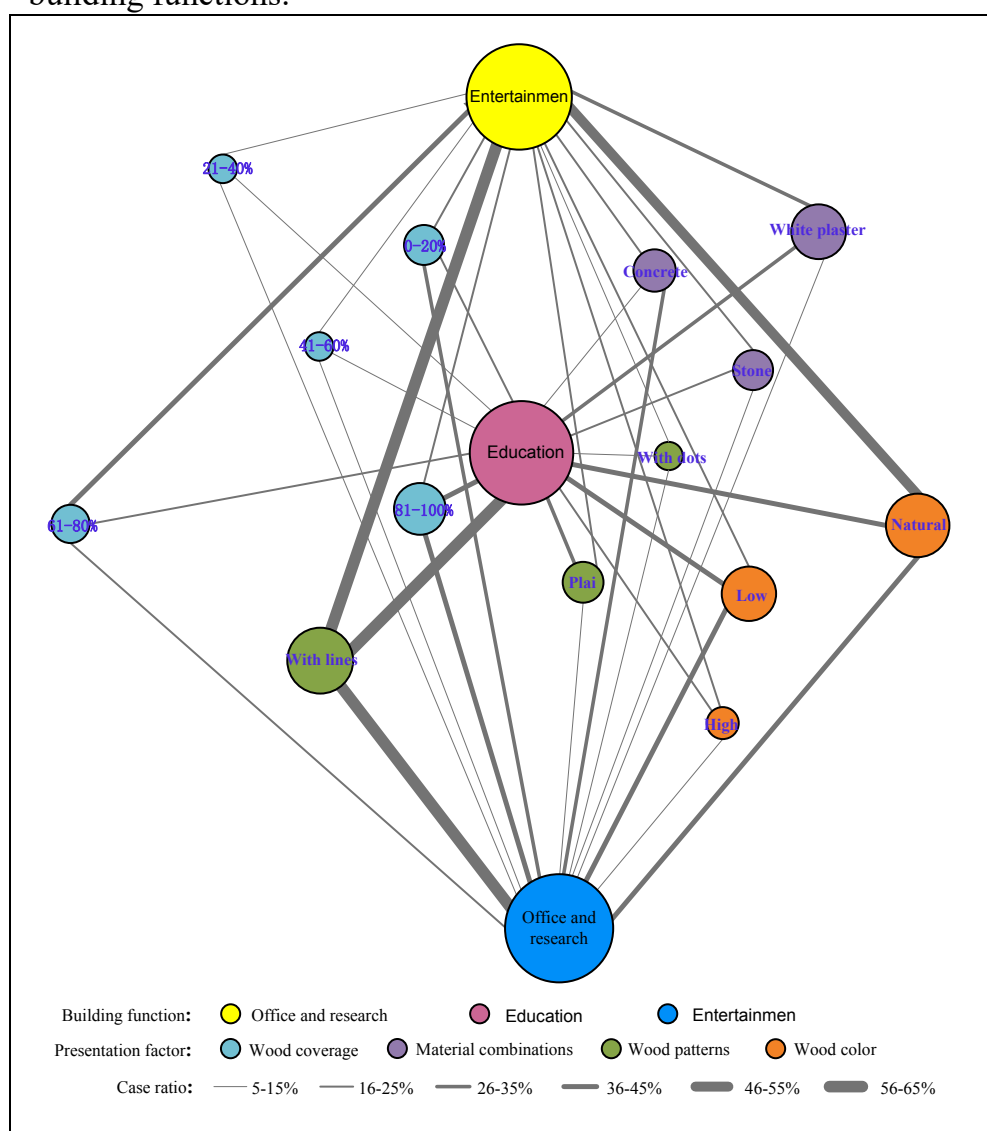

Fig. 4. Relationship network of wood presentation factors and influencing factors. 
Figure 4 shows the obvious commonness and difference of timber for different building functions:

- Commonness: the facade of wood building of different function all tend to use Wood with linear form;

- Difference: 1) For wood coverage:entertainment building tend to choose $61 \%$ - $80 \%$ wood coverage, education building tend to choose $81 \%$ - $100 \%$ wood coverage, while office building choose wood coverage is very obvious, that is, tend to be $0 \%-20 \%$ and $81 \%-100 \%$ range value; 2) For matching materials: entertainment building and education builiding tend to use white plaster, while office building tends to use concrete; 3 ) For wood color: entertainment building tend to be natural wood color, while office building education building tend to be natural wood color or low brightness wood color.

Interpretation for commonness: Because the linear form of wood is easy to transport and construction, and the composition sense is strong, can build a richer skin texture, so it is most commonly used.

Interpretation for difference: entertainment buildings need to reflect a relaxed, comfortable, comfortable temperament, so in wood presentation tend to use Moderately high volume of wood, and mainly through the natural color of wood to create a simple, honest atmosphere, while using white plaster, enhance the contrast between different materials, make a more relaxed atmosphere. Office building needs to reflect the concise, capable, modern temperament. So in wood presentation, there is a phenomenon of wood consumption polarization, that is, either tend to show the whole wood cover, or wood as the finishing touch. Moreover, it tends to use wood color with low brightness to create a personality and rich industrial flavor of the building image. Meanwhile, it also use concrete to enhance enhance the building's modern flavor and industrial sense. The temperament of education building is between entertainment building and entertainment building. Therefore, the wood coverage rate and color show the same characteristics as office buildings, while the matching materials show the same characteristics as entertainment building.

Commonness reflect the overall wood presentation characteristics of the facade of excellent wooden building, which are not affected by building functions, and clear commonalities facilitate the designer to make choice of wood presentation. Difference reflects the wood presentation characteristics affected by the building function, and it is convenient for designers to choose the wood presentation after comprehensive consideration.

\subsection{Analysis of wood presentation characteristics under optimal level combination}

As the factors influencing the presentation of the wood facades are co-related, the analysis of wood presentation characteristics under the joint influence of building function, building shape and building scale has a clear guiding significance. Based on the previous analysis, the optimal level of combination is $\mathrm{A}_{3} \mathrm{~B}_{2} \mathrm{C}_{2}$, that is, the
Medium-scale and pluralistic shape of entertainment wood building is the largest. Therefore this part analyzes the rule of wood application presentation in the case of excellent wood building limited by this level combination.

Figure 5 shows the analysis results for the wood coverage rate and the presentation characteristics of the materials collocation, It is shown that the wood coverage rate of the Medium-scale and pluralistic shape of entertainment wood building tends to be between $61 \%$ and $80 \%$, and the case rate is $32.4 \%$; The matching material tends to choose white plaster and stone. Among them, the proportion of cases with white plaster is $29.2 \%$, and the proportion of cases with stone is $27.8 \%$.

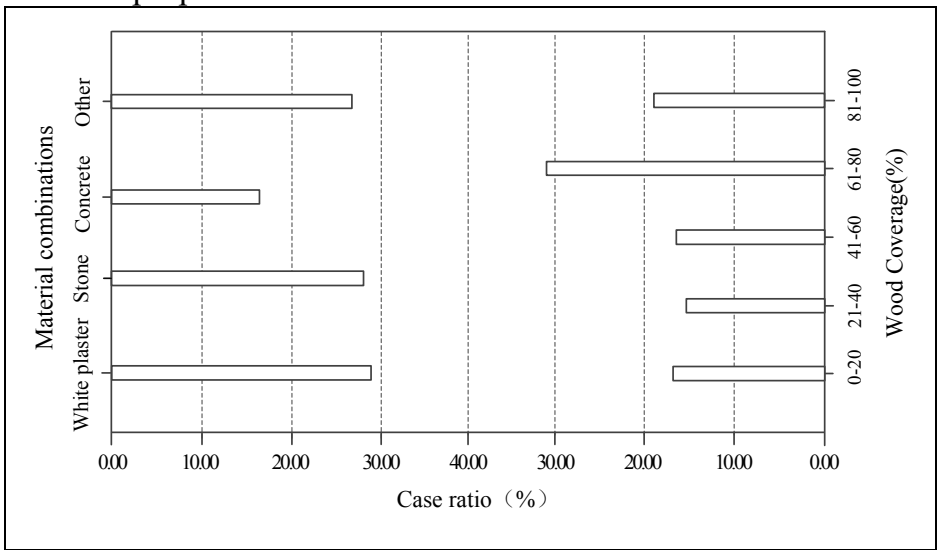

Fig. 5. Wood coverage and material collocation presentation.

Figure 6 shows the analysis results of wood form and wood color presentation characteristics. It shows that the facade of the Medium-scale and pluralistic shape of entertainment wood building tends to use wood in linear form, with the case ratio of $70.6 \%$. The wood color tends to reflect natural wood color, and the case ratio is $65.8 \%$.

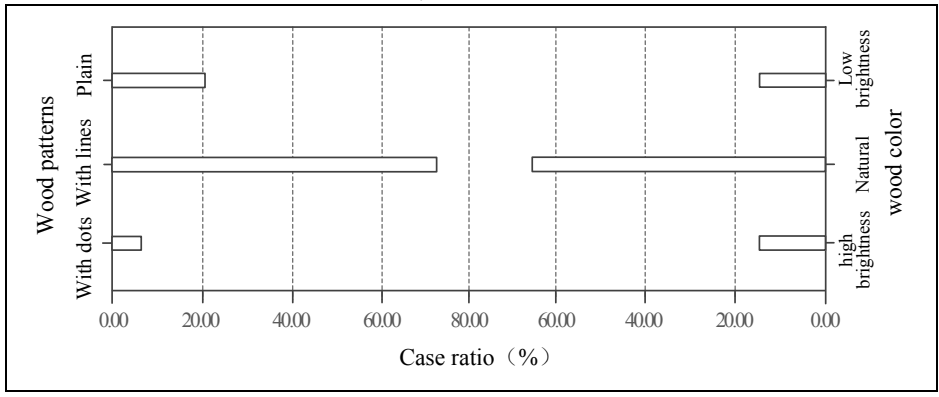

Fig. 6. Wood form and wood color presentation.

The above statistical analysis results can form a clear reference for architectural design. The transformation and combination of wood application variables can provide more expressive techniques. In practice, architects can adopt more practical and efficient expressive techniques according to more specific design requirements. For example, in areas where wood is scarce, it is possible to create a natural, simple, flexible building image by matching less wood with other materials, or to make the wood play a finishing point in the building by changing the color of the wood; in areas where wood is abundant, a higher volume of wood can be used to create a natural and comfortable architectural image by comparing different wood shapes and colors. 


\section{Conclusion}

Based on case statistics of the application presentation of modern wood building, the following conclusions are drawn from the study:

- Significant analysis of influencing factors showed that building function, building shape and building scale had significant impact on wood presentation variables, but functional factors played a leading role; by comparing $\mathrm{K}$ values, wood was more used in Mediumscale and pluralistic shape of entertainment buildings.

- The analysis results of timber presentation rule show that: 1) wood coverage of entertainment wood building facade tended to be in the range of $81 \%-100 \%$, and tended to use natural color line shape wood match with white plastering. 2) wood coverage of office wood building facade tended to be in the range of $0 \%-20 \%$ and $81 \%-100 \%$, and tended to use natural color or intensive color Linear wood match with concrete. 3 ) wood coverage of education wood building facade tended to be in the range of $0 \%-20 \%$ and $81 \%-100 \%$, and tended to use linear or facial form of wood with natural or intensive color match with white plasterer. 4) wood coverage of Medium-scale pluralistic shape of entertainment wood building facade tended to be in the range of $81 \%-100 \%$, and tended to use natural color Linear wood match with white plastering or stone.

This study based on a large number of excellent wood building cases, established a more scientific way of wood using method through focus group and orthogonal experiment. The result will serve as the basis for further research.

\section{Acknowledgments}

This work was supported by the Natural Science Foundation of Heilongjiang Province (General Program, Grant No. E2015010).

\section{References}

1. R. Chen. Diss, Nanjing University of Technology, Research on the Composition and Expression of Modern Timber Architectural Form.(2014)

2. J. Feng. Diss, China University of Mining and Technology, Study on the New Application of Wood in Architecture. (2014)

3. Fell D R. EGU General Assembly Conference. EGU General Assembly Conference Abstracts, Wood in the human environment : restorative properties of wood in the built indoor environment. 7282, (2010)

4. Shuttleworth K, Principal M. Proceedings of the CTBUH 8th World Congress Tall and Green, Typology for a Sustainable Urban Future, Antidotes to Transparency in High Rise Buildings Form and Skin. 481-484, (2008)

5. Kirkegaard A. The Faculty of Engineering and Science, Aalborg University, Aesthetic Qualities of Cross Laminated Timber. (2012)
6. Anders Q. Nyrud K S. Kristian B. WCTE 2016, User Perceptions of Naturalness and the USE of Wood in the Interior environment. (2016) 